\title{
Seeing through carbonate diagenesis: A dual clumped isotope perspective
}

\author{
WEIFU GUO \\ Woods Hole Oceanographic Institution \\ Presenting Author:wfguo@whoi.edu
}

Isotopic composition of carbonate minerals reflects the physicochemical condition of their formation, and provides one of the most important constraints on the evolution of Earth surface environment. However, alterations of carbonate isotope composition during carbonate burial and diagenesis often make it challenging to reconstruct their original deposition conditions. Such alterations also complicate the interpretation of clumped isotope composition of ancient carbonates and hinder the wider application of carbonate clumped isotope thermometer.

Here, I examine the systematics of clumped isotope fractionation during carbonate diagenesis through numerical modeling, and evaluate the potential of the recently developed dual clumped isotope method [1-4] in correcting for diagenetic effects and deriving original carbonate deposition conditions. The dual clumped isotope method examines both ${ }^{13} \mathrm{C}-{ }^{18} \mathrm{O}\left(\Delta_{47}\right)$ and ${ }^{18} \mathrm{O}-{ }^{18} \mathrm{O}\left(\Delta_{48}\right)$ clumping effects in carbonate lattice and has showed great promise for more accurate clumped isotope based paleo-temperature reconstruction [1-4]. I show that the trajectory of $\Delta_{47}-\Delta_{48}$ evolution during carbonate diagenesis depends on multiple factors besides alteration temperature. I compare the model predictions with existing stable isotope and clumped isotope data, and estimate the key parameters controlling the kinetics of clumped isotope alteration. I argue that the dual clumped isotope method provides important additional constraints on carbonate diagenesis and offers new opportunities to reconstruct the original deposition conditions of diagenetically altered carbonates. The implications of these findings for other clumped isotope systems (e.g., methane) will also be discussed.

[1] Guo and Zhou (2019), Geochim. Cosmochim. Acta, 267, 196-226; [2] Guo (2020), Geochim. Cosmochim. Acta, 268, 230257; [3] Fiebig et al. (2019), Chem. Geol., 522, 186-191; [4] Bajnai et al. (2020), Nat. Commun., 11: 4005. 